\title{
Determination of endogenous methane formation by
}

\section{photoacoustic spectroscopy}

E Tuboly $^{1^{*}}$, A Szabó $^{2 *}$, G Erős $^{3}$, Á Mohácsi $^{4}$, G Szabó $^{2,4}$, R Tengölics $^{5}$, G Rákhely $^{5}$ and M $\operatorname{Boros}^{1}$

${ }^{1}$ Institute of Surgical Research, Faculty of Medicine, University of Szeged, Szeged, Hungary

${ }^{2}$ Department of Optics and Quantum Electronics, Faculty of Science and Informatics, University of Szeged, Szeged, Hungary

${ }^{3}$ Department of Oral Biology and Experimental Dental Research, Faculty of Dentistry, University of Szeged, Szeged, Hungary

${ }^{4}$ MTA-SZTE Research Group on Photoacoustic Spectroscopy, Szeged, Hungary

${ }^{5}$ Department of Biotechnology, Faculty of Science and Informatics, University of Szeged, Szeged, Hungary

*These authors contributed equally to this paper.

Corresponding author:

Mihály Boros MD, PhD, DSc

Institute of Surgical Research, University of Szeged, P.O. Box 427, H-6701 Szeged, Hungary

E-mail: boros.mihaly@med.u-szeged.hu

Phone: +36-62-545103

Fax: $+36-62-455743$

Running head: Quantification of endogenous methane generation 


\begin{abstract}
Aerobic methane generation was demonstrated earlier in plants and eukaryotes under various stress conditions. Our aims were to develop a real-time and noninvasive detection system for monitoring the methane production of small animals and humans with our without exposure to various treatments. A near-infrared diode laser technique was employed with photoacoustic spectroscopy to monitor a methane-containing atmosphere online. The whole-body methane generation of anesthetized mice and rats was determined under baseline conditions and following reduction of the intestinal methanogenic flora or after lipopolysaccharide administration. Single-breath methane analyses were also carried out in a cross-sectional clinical study in order to obtain comparative human data. The whole-body methane production of mice was significantly decreased after antibiotic treatment $\left(\mathrm{M}: 1.71 \mathrm{ppm} / \mathrm{cm}^{2} 10^{3} ; \mathrm{p} 25: 1.5\right.$ $\mathrm{ppm} / \mathrm{cm}^{2} 10^{3} ; \mathrm{p} 75: 2.11 \mathrm{ppm} / \mathrm{cm}^{2} 10^{3}$ ) and increased significantly in endotoxemia (M: 4.53 $\mathrm{ppm} / \mathrm{cm}^{2} 10^{3} ; \mathrm{p} 25: 4.37 \mathrm{ppm} / \mathrm{cm}^{2} 10^{3} ; \mathrm{p} 75: 5.38 \mathrm{ppm} / \mathrm{cm}^{2} 10^{3}$ ), while no difference was observed between the rat groups. The methane content of the exhaled breath in humans was found to be between 0 and $37 \mathrm{ppm}$. Photoacoustic spectroscopy is a reliable tool with which to monitor the in vivo dynamics of stress-induced methane production in laboratory animals, even in a very low concentration range.
\end{abstract}

Key words: near-infrared diode laser technique, methanogenesis, whole-body methane generation, hypoxia, photoacoustic spectroscopy 


\section{Introduction}

Many gases produced in the human body are biologically active. Signalling roles have been demonstrated for nitric oxide (NO), carbon monoxide (CO) and hydrogen sulphide $\left(\mathrm{H}_{2} \mathrm{~S}\right)$, and research on gas mediators and derivatives has become a topic of considerable interest. Endogenous methane $\left(\mathrm{CH}_{4}\right)$ production may well be such an area.

$\mathrm{CH}_{4}$ plays important roles in both tropospheric and stratospheric chemistry [1], but the biological role of $\mathrm{CH}_{4}$ in mammalian physiology is largely unmapped, and the significance of endogenous bacterial generation is still not known with certainty [2]. Furthermore, the possibility of $\mathrm{CH}_{4}$ emission from living plants has been revealed under aerobic conditions [3], and nonmicrobial $\mathrm{CH}_{4}$ release has also been confirmed in eukaryotic cells [4-8]. Nonbacterial methanogenesis was recently demonstrated in various in vitro and in vivo systems after transient oxygen deprivation [9-13].

In humans, bacterial $\mathrm{CH}_{4}$ present in the intestinal tract is excreted via the lungs, and breath testing has therefore become a tool with which to diagnose certain gastrointestinal conditions $[14,15]$. In such cases, the output of $\mathrm{CH}_{4}$ or $\mathrm{CH}_{3}$ group-containing compounds is usually measured in exhaled air samples by means of gas chromatography (GC) [16] or GC-mass spectrometry [17]. Nevertheless, traditional methods of breath analysis have limitations and the risk of possible artefacts is high [18]. Furthermore, discontinuous detection methods cannot reflect the overall profile of in vivo $\mathrm{CH}_{4}$ generation because the pulmonary route is certainly not exclusive. $\mathrm{CH}_{4}$ is distributed evenly across membrane barriers, and its production is therefore manifested not only in the exhaled air but also through body surfaces. Indeed, a recent study has shown the uniform release of $\mathrm{CH}_{4}$ through the skin in healthy individuals [19]. It follows that improved methods are needed to define the exact magnitude of $\mathrm{CH}_{4}$ discharge through the overall body surface.

Our main aim was to design a compact and versatile setup with which to determine the whole body $\mathrm{CH}_{4}$ release in living, unrestrained small animals. The goal was to develop and validate a reliable noninvasive tool via which to follow $\mathrm{CH}_{4}$-producing phenomena in rodents, specifically and reproducibly. For $\mathrm{CH}_{4}$ detection, we employed diode laser-based photoacoustic spectroscopy (PAS), which has proved its relevance in life science applications [20-22]. As the distribution of the endogenous bacterial and nonbacterial metabolic pathways of $\mathrm{CH}_{4}$ generation remains unidentified, in 
the second part of our study we set out to determine the $\mathrm{CH}_{4}$ production profile of rodents exposed to potentially inflammatory or anti-inflammatory treatment targeting the intestinal methanogenic flora. Once the procedure had been validated, a further and minor aim was to use the PAS detection system in healthy humans to obtain data that could be compared with the findings of other studies and methods applied for $\mathrm{CH}_{4}$ breath tests.

\section{Materials and Methods}

The animal experiments were performed on a total of 16 male Sprague-Dawley rats (weighing 220-300 g) and 24 SKH-1 hairless mice (weighing 32-36 g) in accordance with the National Institutes of Health guidelines on the handling and care of experimental animals. The study was approved by the Animal Welfare Committee of the University of Szeged. The animals were housed in plastic cages under 12-h dark-light cycles. Standard laboratory chow and drinking water were provided ad libitum. The human protocol included 39 healthy females (aged 13-58 years) and 44 males (aged 7-69 years) who were randomly assigned to the study. Each of these participants signed an informed consent form before the start of the experiments, and the procedures were performed with the approval of the Ethical Committee of the University of Szeged.

\subsection{Experimental protocol}

\subsubsection{Rat study}

The 16 rats were divided into 2 groups. The measurements on untreated healthy controls (Group 1, n=9) were compared with those on the antibiotic-pretreated group (Group 2, n=7), which received rifaximin (10 $\mathrm{mg} \mathrm{kg}^{-1} \mathrm{day}^{-1}$, Alfa Wasserman, West Caldwell, NJ, USA) orally for 3 days. This procedure resembles the clinical practice of targeting the gastrointestinal bacterial flora; the rifaximin dose was chosen with regard to the overall minimum inhibitory concentration $\left(25 \mu \mathrm{g} \mathrm{ml}^{-1}\right)$ at which $50 \%$ of the strains (which contain methanogenic archae) are inhibited [23]. The whole-body $\mathrm{CH}_{4}$ emission was measured every second day.

\subsubsection{Mouse study}

The 24 mice were randomly allocated into 3 groups. Group $1(n=8)$ served as untreated control. The animals in Group $2(\mathrm{n}=8)$ underwent intestinal flora eradication: $10 \mathrm{mg} \mathrm{kg}^{-1}$ of rifaximin 
was administered orally via gavage. This treatment was repeated 2 days later. After another period of 2 days, the $\mathrm{CH}_{4}$ emission of the animals was determined. In Group $3(\mathrm{n}=8)$, lipopolysaccharide (LPS) was administered ( $5 \mathrm{mg} \mathrm{kg}^{-1}$ i.p.) and $3 \mathrm{~h}$ later the $\mathrm{CH}_{4}$ release was recorded.

\subsubsection{Human study}

Measurements were performed at preset times (the same hour of day) just before the first meal. The participants were subgrouped as by males $(n=44)$ or females $(n=39)$ and as children (aged $\leq$ 20 years; $n=42$ ) or adults (aged $\geq 21$ years; $n=41$ ). $T$ he $\mathrm{CH}_{4}$ concentration of the exhaled air was measured. Participants were considered to be $\mathrm{CH}_{4}$ producers if the exhaled $\mathrm{CH}_{4}$ concentration exceeded 1 part per million (ppm).

\subsection{Methane detection}

PAS is a special mode of optical absorption spectroscopy which measures optical absorption indirectly via the conversion of absorbed light energy into acoustic waves [24, 25]. The amplitude of the generated sound is directly proportional to the concentration of the absorbing gas component. A standard photoacoustic gas detector incorporates the following main parts: an excitation source, a photoacoustic cell, a gas-handling system, and controlling and data-processing units. The gas sample is passed through the photoacoustic cell, in which signal generation takes place, and the photoacoustic signal produced is then detected by a microphone.

The excitation source of the present system was a fiber-coupled distributed-feedback diode laser (with $15 \mathrm{~mW}$ output power; from NTT Electronics, Tokyo, Japan) emitting at around a $\mathrm{CH}_{4}$ absorption line near $1650 \mathrm{~nm}$ [26]. Diode lasers provide excellent selectivity in consequence of their narrow spectral line width $(2 \mathrm{MHz})$. The shape of the $\mathrm{CH}_{4}$ absorption line could be measured by tuning the wavelength of the laser through adjustment of its temperature (typically $0.1 \mathrm{~nm}^{\circ} \mathrm{C}^{-1}$ ). The emission wavelength could therefore be adjusted accurately so as to be at the maximum of the absorption line, which ensured high spectral selectivity. Additionally, near-infrared distributedfeedback lasers are cost-effective, have long lifetimes (of the order of ten thousand hours of operation) and provide excellent modulation possibilities.

The laser beam was collimated by a lens (Thorlabs Inc., Newton, NJ, USA) and was directed through a dual-pass photoacoustic cell which contained a cylindrical resonator (length $3 \mathrm{~cm}$ and 
diameter $0.43 \mathrm{~cm}$ ). The diode laser was wavelength modulated at $5.2 \mathrm{kHz}$, corresponding to the frequency of the first longitudinal mode of the acoustic resonator, consequently first derivative of the spectrum was obtained. The modulation depth was optimized to achieve the best signal-to-noise ratio and it was found to be $13.5 \%$. The quality factor of the resonator was around 6 . This relatively small quality factor ensured that resonance frequency (modulation frequency) tracking was not required because photoacoustic signal decrease caused by altering gas composition of the samples (the increased $\mathrm{CO}_{2}$ and water vapor concentrations of the exhaled air compared to ambient air) was less than 3\%. The generated sound was measured by an electret microphone (Knowles, Itasca, IL, USA). The signal of the microphone was amplified (by a factor of 6000) and the photoacoustic signal was measured using digital lock-in technique [27]. Acoustic filters were attached to the resonator in order to filter out disturbing noise. The photoacoustic cell and the gas-handling system were made of stainless steel. The photoacoustic cell was temperature-stabilized at $40{ }^{\circ} \mathrm{C}$ in order to inhibit the condensation of water vapour from the breath. Gas from the sampling chamber was drawn through the photoacoustic cell by a membrane pump (Rietschle Thomas GmbH, Puchheim, Germany) and the gas flow rate was controlled by a rotameter (Yokogawa Electrical Corporation, Tokyo, Japan). An electronic device (Videoton Holding Plc., Székesfehérvár, Hungary) provided overall system control and measurement automatization [27]. It incorporated a laser driver and temperature controller, a microphone amplifier, a data-processing unit, and several input and output ports.

The complete photoacoustic measuring system (excluding the sampling chamber) was built into an easily portable, 19"4U instrument box (figure 1). The device operated without the addition of any chemicals. 


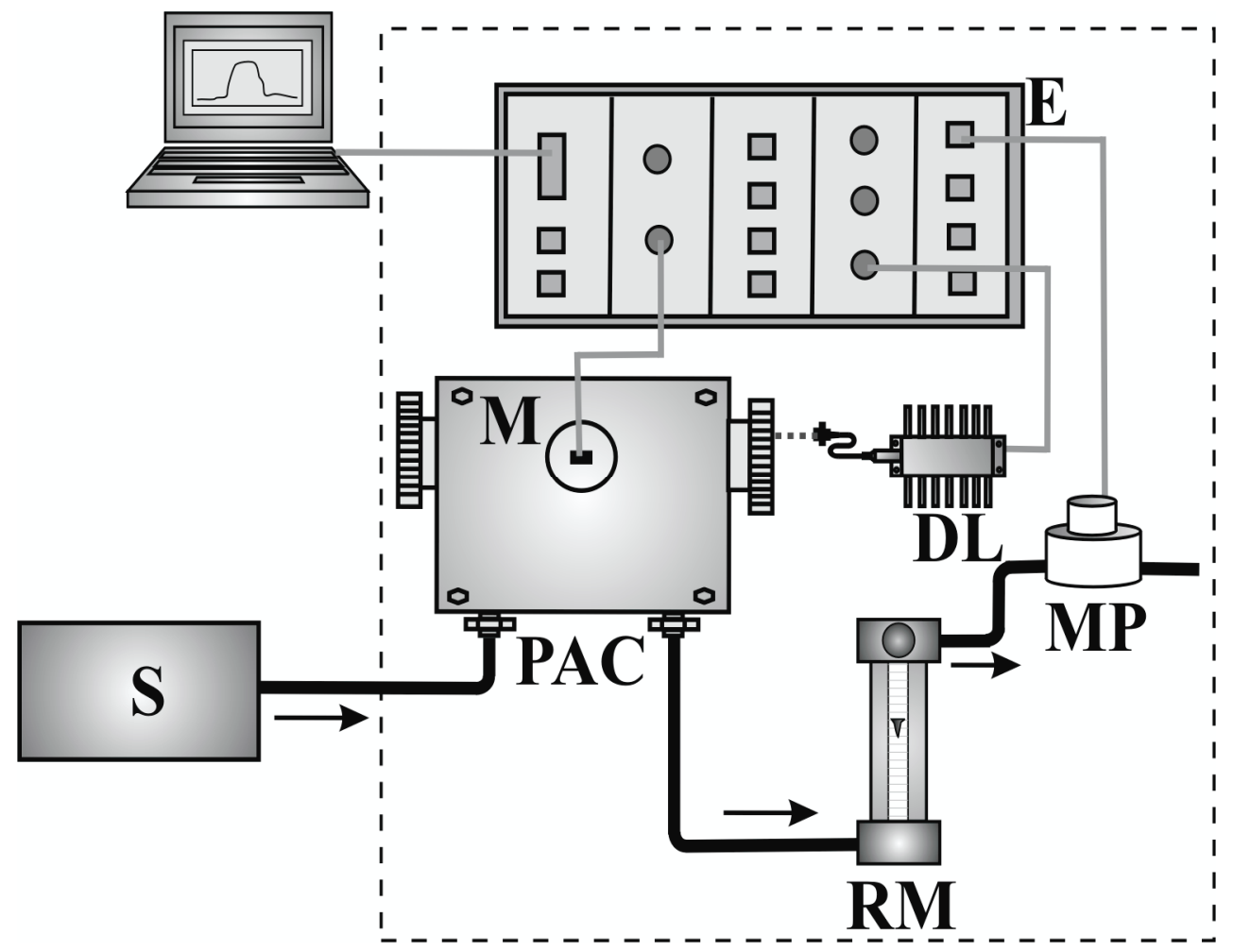

Figure 1. Schematic representation of the device and the photoacoustic detection setup. Gas samples (S) are drawn by a membrane pump (MP) into the photoacoustic cell (PAC), where the signal is generated by a diode laser (DL) and detected by a microphone (M). The gas flow rate can be adjusted with a rotameter $(\mathrm{RM})$. The electronic unit $(\mathrm{E})$ provides system control and data processing, and a computer presents data graphically. Arrows indicate the gas flow direction. The dashed line encloses the components built into a $19 " 4 \mathrm{U}$ instrument box.

\subsubsection{Calibration}

The system was calibrated by preparing various gas mixtures from a cylinder of $995 \mathrm{ppm}^{\mathrm{CH}_{4}}$ in synthetic air (certified calibration gas with a relative uncertainty of $2 \%$ from Messer Hungarogas, Budapest, Hungary) and from humidified ambient air [28] by means of mass-flow controllers (Mykrolis, Brooks Instrument, Hatfield, PA, USA). The gas was humidified with a gas bubbler containing saturated sodium chloride solution; relative humidity in the photoacoustic cell was about $60 \%$ RH. The mass-flow controllers were calibrated with a digital bubble flowmeter (Optiflow, Agilent Technologies Inc., Santa Clara, CA, USA). The $\mathrm{CH}_{4}$ concentrations of the premixed gases were $1.8,2.3,2.9,3.8,6.8,11.8,21.8,37.9,66.0,101.6 \mathrm{ppm}$. The $\mathrm{CH}_{4}$ concentration of the ambient 
air (1.8 ppm) [29] was considered to be constant during the measurement time, and was taken into consideration when the gas standards were mixed. Additionally, a mixture containing $22.5 \mathrm{ppm} \mathrm{CH}_{4}$ in 5 vol \% carbon dioxide $\left(\mathrm{CO}_{2}\right)$ in air was prepared. A linear relationship was found between the photoacoustic signal and the concentration of $\mathrm{CH}_{4}$ (figure 2). Linear regression of the data led to the following equation $\left(n=10, R^{2}=0.9999\right)$ : $S=21.7 \pm 1.4+9.08 \pm 0.04 c$, where $S$ is the photoacoustic signal in $\mu \mathrm{V}$ and $\mathrm{c}$ is the concentration of $\mathrm{CH}_{4}$ in ppm. Errors of equation terms are corresponding to the errors of the linear regression.

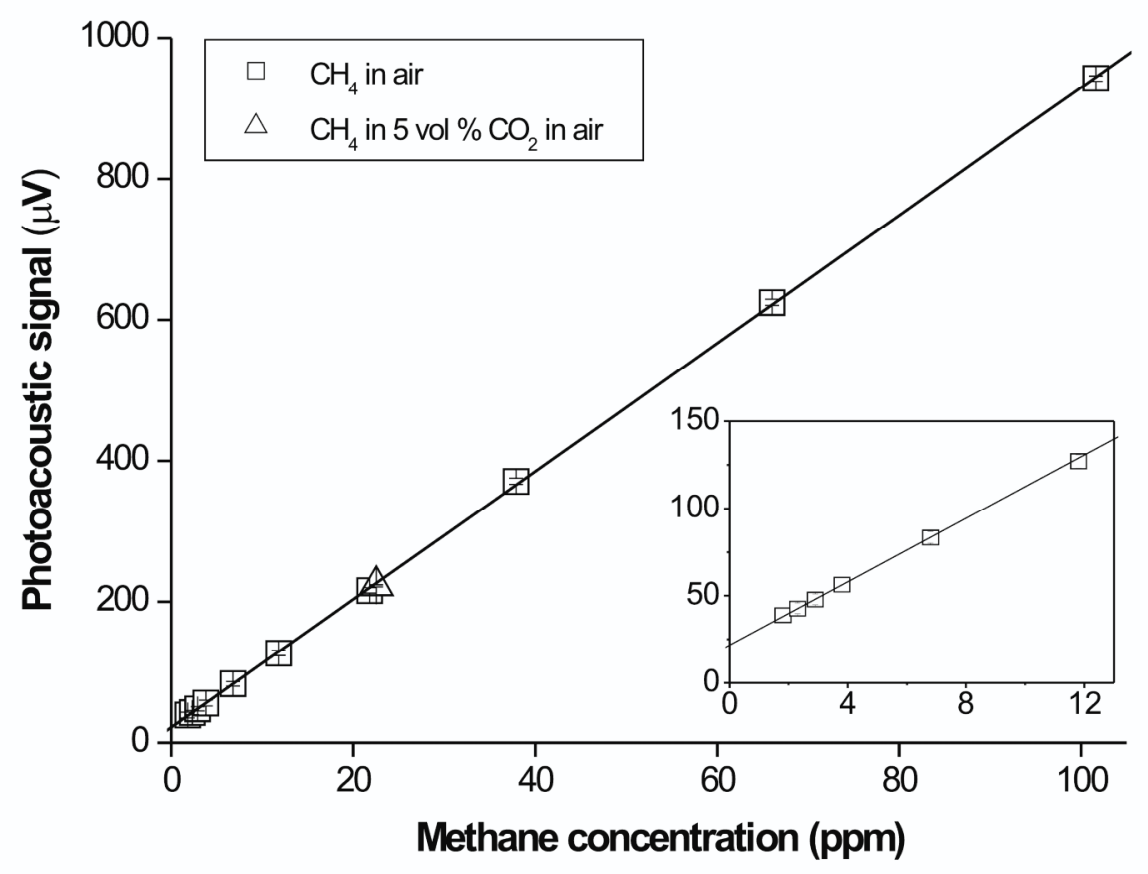

Figure 2. Photoacoustic signal as a function of $\mathrm{CH}_{4}$ concentration. The solid line reflects the linear regression of the data $\left(n=10, R^{2}=0.9999\right)$. For clarity, the inset shows the plot for low $\mathrm{CH}_{4}$ concentrations at higher magnifications. The error bars indicate three times the standard deviation of the data, but cannot be separated from the symbols.

The minimum detectable concentration was calculated as the triple standard deviation $(3 \sigma)$ of the data at zero $\mathrm{CH}_{4}$ concentration $(0.9 \mu \mathrm{V})$, divided by the sensitivity, which is the slope of the calibration curve $(9.08 \mu \mathrm{V})$. The minimum detectable concentration was found to be $0.3 \mathrm{ppm}$, with an 
integration time of $12 \mathrm{~s}$. The intercept of the linear regression $(21.7 \mu \mathrm{V})$ can be interpreted as the photoacoustic background signal.

Calibrations conducted in April 2012 and March 2013 indicated that the instrument demonstrates long-term stability. The sensitivity of the system changed by less than $2 \%$ in 11 months (figure 3 ).

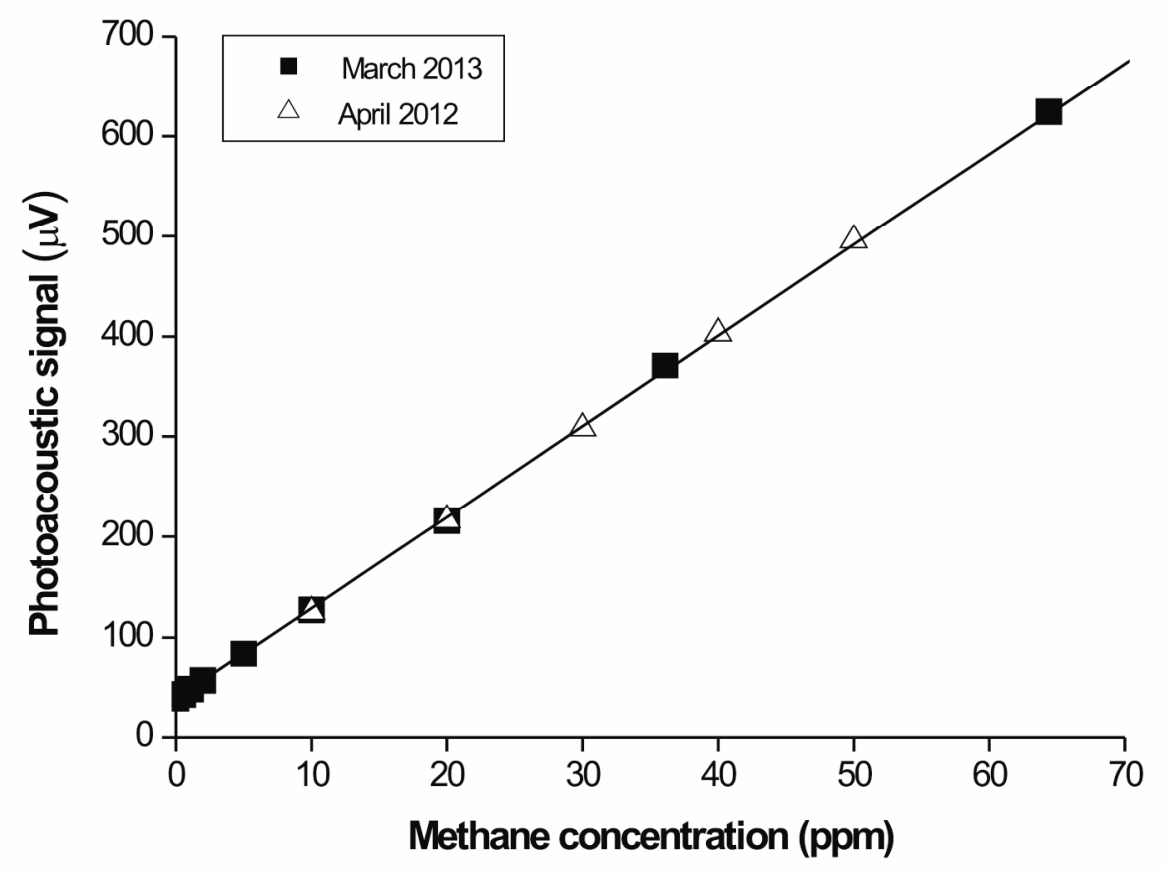

Figure 3. Photoacoustic signal as a function of $\mathrm{CH}_{4}$ concentration. Closed squares and open triangles denote data form calibration measurements made in March 2013 and April 2012, respectively.

\subsubsection{Verification by gas chromatography}

The calibration of the photoacoustic system was verified with a previously calibrated Agilent 6890 GC instrument equipped with a split-splitless inlet HP-Molsieve $5 \AA$ column $(30 \mathrm{~m} * 0.53 \mathrm{~mm} * 25 \mu \mathrm{m})$ and a flame ionization detector. Hydrogen was used as carrier gas. The inlet parameters were as follows: temperature $150{ }^{\circ} \mathrm{C}$, total flow $40.5 \mathrm{ml} \mathrm{min}^{-1}$. The oven and detector temperatures were $60{ }^{\circ} \mathrm{C}$ and $300{ }^{\circ} \mathrm{C}$, respectively. $500 \mu \mathrm{l}$ of gas mixture was injected manually into the GC instrument with a Hamilton 1750 microsyringe equipped with a pt5 endpoint needle. The analysis time was 1 min per sample. The separation and detection of $\mathrm{CH}_{4}$ guaranteed the selectivity of the method, and therefore no interference was observed. The measurements were made on the 
premixed gas standards used for the calibration of the photoacoustic device (1.8-66.0 ppm). The standard deviation of the GC data was calculated from four measurements and proved to be $4.7 \%$ on average. The $\mathrm{CH}_{4}$ content of the ambient air was detected with a signal to noise ratio of 10 to 1 .

The measurement results of GC and PAS were in good agreement; the average difference was $\sim 1 \%\left(\mathrm{n}=8, \mathrm{R}^{2}=0.9993\right)$.

\subsubsection{Cross-sensitivity}

The cross-sensitivities for common components of breath and ambient air were examined, but no measurable instrument response was found for several vol $\%$ of $\mathrm{CO}_{2}$ (figure 2) or water vapor. In accordance with the absorption spectra of the compounds based on the HITRAN database [30], the absorbance of $\mathrm{CH}_{4}$ is 8 orders of magnitude greater than that of $\mathrm{H}_{2} \mathrm{O}, \mathrm{CO}$ or $\mathrm{CO}_{2}$ at the measurement wavelength of $1650.96 \mathrm{~nm}$. Moreover, the HITRAN database indicates that there are no $\mathrm{H}_{2} \mathrm{~S}$, ammonia $\left(\mathrm{NH}_{3}\right)$ or $\mathrm{NO}$ absorption lines between 1.60 and $1.70 \mu \mathrm{m}$.

\subsubsection{Sampling methods}

Adequate sampling, which is essential for gas measurements, poses a great challenge, particularly in the case of living organisms. Contamination from ambient air, losses, dilution or adsorption-desorption processes on walls can cause significant inaccuracies, even when commercially available sampling bags are used. Separated steps of sampling and sample preparation are timeconsuming, limit convenience and introduce handling errors [18]. Since $\mathrm{CH}_{4}$ has a high diffusion capacity, samples must be analyzed without delay. PAS-based gas analysis does not require gas preparation (including preconcentration, purification or cold trapping). It permits direct gas sampling; consequently, the gas sample flows directly to the photoacoustic cell.

\subsubsection{Sampling in rodents}

Two sampling chambers were constructed for the animals, with regard to their average size and the air volume required for their normal respiration. The chambers and the gas-sampling system were made of glass and stainless steel, respectively, in order to minimize the adverse effects of adsorption-desorption. A $180 \mathrm{~cm}^{3}$ sampling chamber was prepared to accumulate the $\mathrm{CH}_{4}$ emanating from a mouse, and another sampling chamber was required for the measurements on rats (volume: $2510 \mathrm{~cm}^{3}$ ). The chamber consisted of a glass cylinder and two metal plates, a fixed one and a 
removable one, and a gas outlet port was situated on the fixed plate. The chamber included a removable stainless steel grid, ensuring that virtually the whole body surface of the animal remained uncovered. An animal was laid on the grid and placed into the chamber, and the cylinder tube was then closed with the removable plate.

In the event of continuous sampling, a constant gas concentration is established when the number of gas molecules released from the animal per unit time is equal to the number of gas molecules transferred by the volume of sampled gas per unit time. In other words, if the sampling flow rate is constant, a well-defined $\mathrm{CH}_{4}$ emission corresponds to a given steady $\mathrm{CH}_{4}$ concentration. It was found that the $\mathrm{CH}_{4}$ concentration increased immediately after the animal was placed in the chamber, and a fixed time interval during which there was no gas sampling from the chamber was therefore included to accelerate the building-up of a steady $\mathrm{CH}_{4}$ concentration. This "accumulation" period was established empirically and optimized for each sampling chamber to abbreviate the procedural time. It was found that 10 min was sufficient for a constant $\mathrm{CH}_{4}$ concentration to be achieved in the mouse chamber, while in case of the rat the optimal time for $\mathrm{CH}_{4}$ "accumulation" was found to be $8 \mathrm{~min}$.

As concerns the determination of the $\mathrm{CH}_{4}$ concentration of the room air, an initial fluctuation was regularly observed for 1-2 min (depending on the day, the season, the number of persons in the room, etc.) and approximately 5 min was needed to obtain a stable $\mathrm{CH}_{4}$ signal. During this phase, the chamber was continuously flushed with room air (i.e. the inlet and outlet of the chamber were open) and the baseline $\mathrm{CH}_{4}$ level was determined for $5 \mathrm{~min}$. The animal was then placed in the glass chamber and the "accumulation" period was started. After the "accumulation" period, the membrane pump began to draw gas through the photoacoustic cell at a flow rate of $4.5 \mathrm{~cm}^{3} \min ^{-1}$; the plate with which the chamber was closed allowed the sampled gas volume to be replaced with ambient air. In each measurement, a plateau level was reached after 6-8 min, and thereafter remained steady until the end of the 10-min observation period. The whole-body emissions were calculated without the background $\mathrm{CH}_{4}$ level, and the values were referred to the body surface area of the animals. Figure 4 shows a typical measurement curve in a mouse. If the $4.5 \mathrm{~cm}^{3}$ gas sample sampled in 1 min contains $1 \mathrm{ppm}$ $\mathrm{CH}_{4}$ (without the background $\mathrm{CH}_{4}$ level), then the $\mathrm{CH}_{4}$ emission is $2.910^{-9} \mathrm{~g} \mathrm{~min}^{-1}$. In order to simplify evaluations, the $\mathrm{CH}_{4}$ release is given in $\mathrm{ppm} /\left(\mathrm{cm}^{2} 10^{3}\right)$. 


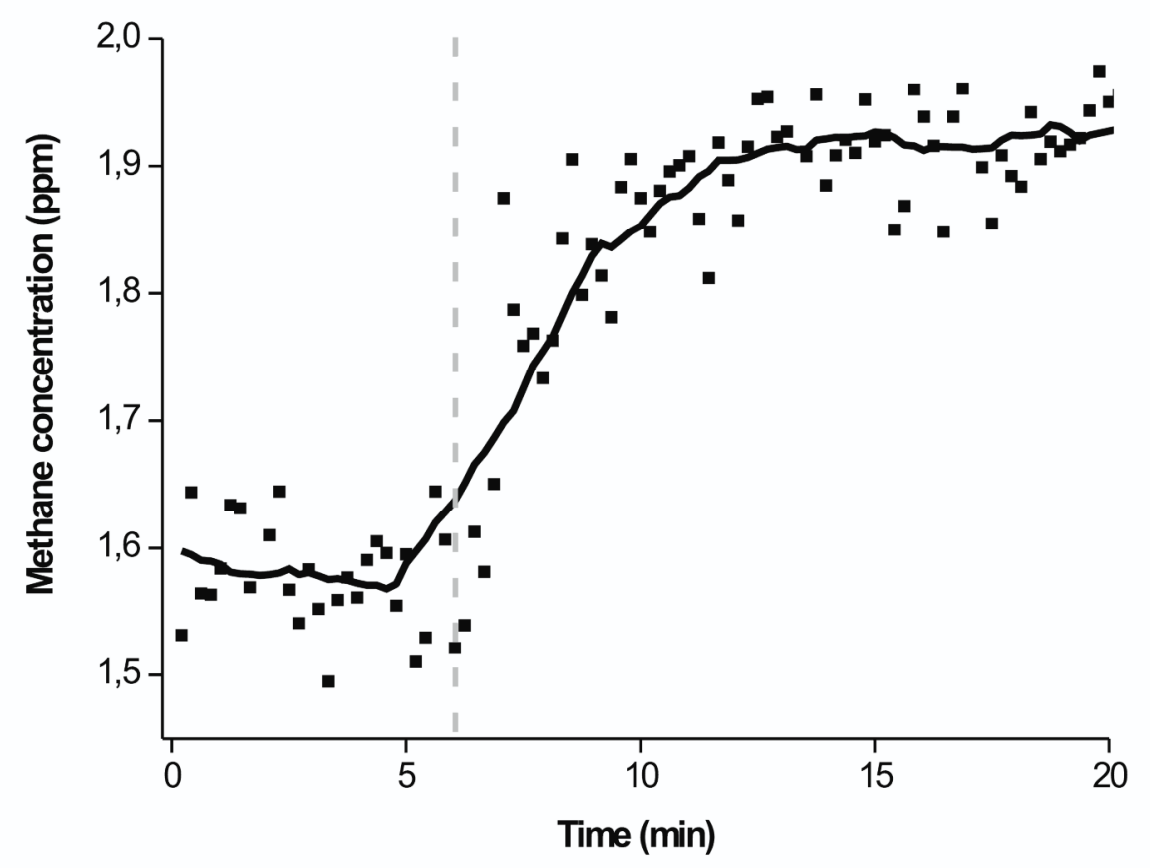

Figure 4. Control $\mathrm{CH}_{4}$ measurement in a mouse. For several min, the methane concentration of room air was measured, and the vertical dashed line indicates the time when the gas flow from the chamber started. Solid grey curve shows moving average over 20 points. Baseline measurements are not shown for the total "accumulation" time (which was $10 \mathrm{~min}$ ).

\subsubsection{Sampling in humans}

In the case of human measurements, the $\mathrm{CH}_{4}$ concentration of the room air was determined and used as baseline in the calculations of the $\mathrm{CH}_{4}$ emission. Afterwards, the subject was asked to breathe normally and the expired air was directed into a glass flask (volume: $200 \mathrm{~cm}^{3}$ ). The optimal time for the attainment of a steady $\mathrm{CH}_{4}$ concentration proved to be between 1 and 3 min with a flow rate of $30 \mathrm{~cm}^{3} \min ^{-1}$.

\subsection{Statistical analysis}

Data analysis was performed with a statistical software package (SigmaStat for Windows, Jandel Scientific, Erkrath, Germany). Friedman repeated measures analysis of variance on ranks was 
applied within groups. Time-dependent differences from the baseline $(0 \mathrm{~min})$ for each group were assessed by Dunn's method, and differences between groups were analyzed with Kruskal-Wallis oneway analysis of variance on ranks, followed by Dunn's method for pairwise multiple comparisons. The Mann-Whitney U-probe was applied to assess the differences between human samples. In the figures, median values and $75^{\text {th }}$ and $25^{\text {th }}$ percentiles are given. $\mathrm{p}$ values $<0.05$ were considered significant.

\section{Results}

\subsection{Whole-body $\mathrm{CH}_{4}$ release from rats}

We performed repeated analyses at 2-day intervals to follow the $\mathrm{CH}_{4}$ profile of each animal (figure 5). At the end of the investigation, no elevation was noted in the control (M: $1.34 \mathrm{ppm} / \mathrm{cm}^{2} 10^{3}$; p25: $1.08 \mathrm{ppm} / \mathrm{cm}^{2} 10^{3} ; \mathrm{p} 75: 1.60 \mathrm{ppm} / \mathrm{cm}^{2} 10^{3}$ ) or antibiotic-treated (M: $1.60 \mathrm{ppm} / \mathrm{cm}^{2} 10^{3} ; \mathrm{p} 25: 0.94$ $\mathrm{ppm} / \mathrm{cm}^{2} 10^{3} ; \mathrm{p} 75: 1.67 \mathrm{ppm} / \mathrm{cm}^{2} 10^{3}$ ) groups relative to the first, baseline measurement. The elimination of the intestinal bacteria led to a considerable decrease in $\mathrm{CH}_{4}$ emission in the first measurement, but it remained measurable (M: $1.14 \mathrm{ppm} / \mathrm{cm}^{2} 10^{3} ; \mathrm{p} 25: 0.85 \mathrm{ppm} / \mathrm{cm}^{2} 10^{3} ; \mathrm{p} 75: 1.31$ $\left.\mathrm{ppm} / \mathrm{cm}^{2} 10^{3}\right)$

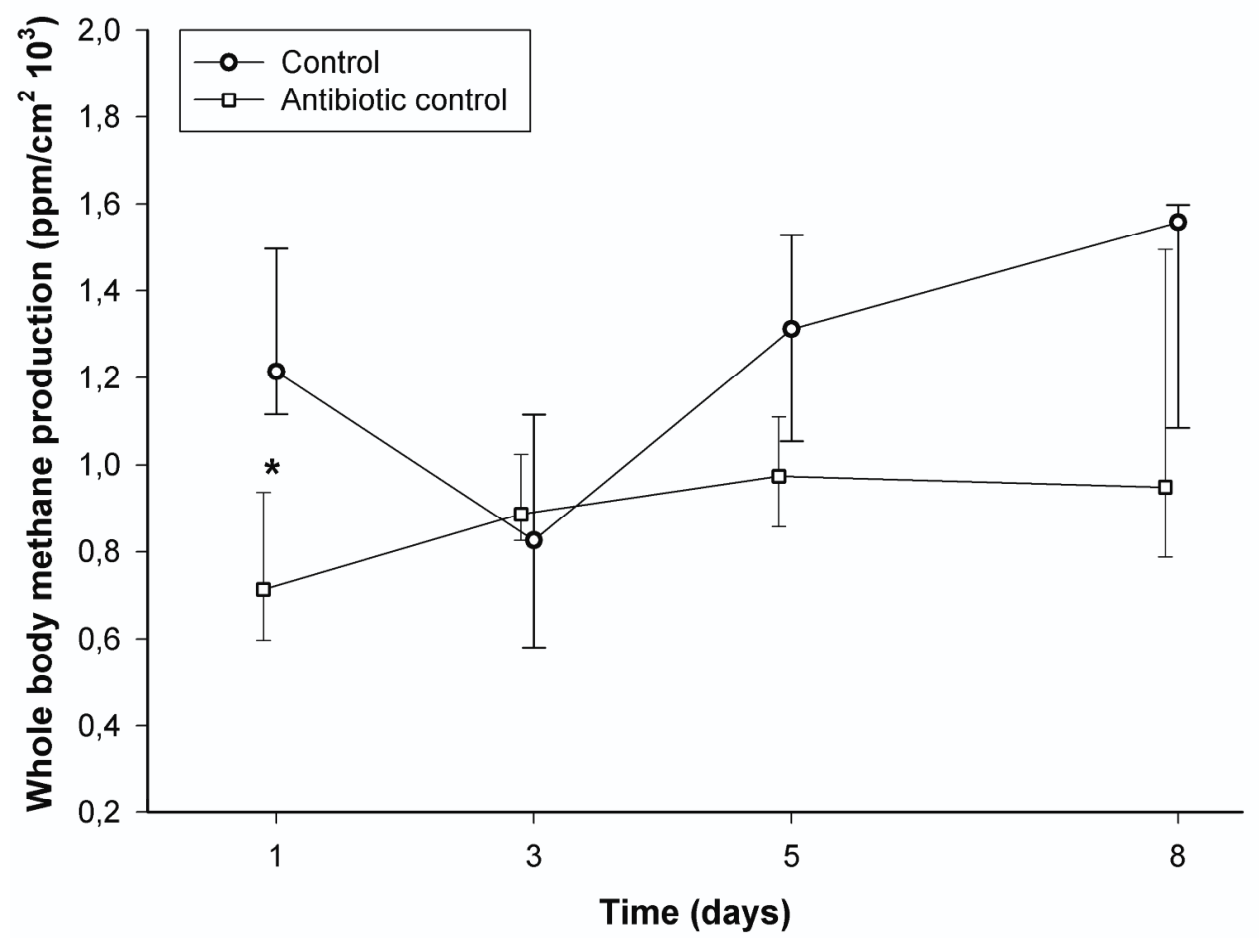


Figure 5. Whole-body $\mathrm{CH}_{4}$ production of rats on days $1,3,5$ and 8 of the protocol. Empty circles joined by a continuous line: control group; empty squares joined by a continuous line: rifaximintreated group. At the time of the first measurement shown, the antibiotic-treated group had been pretreated for 3 days. Median values and $75^{\text {th }}$ and $25^{\text {th }}$ percentiles are given. $\mathrm{p}<0.05$ was considered statistically significant. $* \mathrm{p}<0.05$ vs. control.

\subsection{Whole-body $\mathrm{CH}_{4}$ release from mice}

A measurable $\mathrm{CH}_{4}$ release was observed in each animal in the control group (M: $3.25 \mathrm{ppm} / \mathrm{cm}^{2}$ 10 $; \mathrm{p} 25: 3.00 \mathrm{ppm} / \mathrm{cm}^{2} 10^{3} ; \mathrm{p} 75: 3.89 \mathrm{ppm} / \mathrm{cm}^{2} 10^{3}$ ) (figure 6). The antibiotic treatment led to a significantly lower but still measurable $\mathrm{CH}_{4}$ emission (M: $1.71 \mathrm{ppm} / \mathrm{cm}^{2} 10^{3} ; \mathrm{p} 25: 1.50 \mathrm{ppm} / \mathrm{cm}^{2} 10^{3}$; p75: $2.11 \mathrm{ppm} / \mathrm{cm}^{2} 10^{3}$ ). However, the application of LPS increased the $\mathrm{CH}_{4}$ production considerably (M: $4.53 \mathrm{ppm} / \mathrm{cm}^{2} 10^{3} ; \mathrm{p} 25: 4.37 \mathrm{ppm} / \mathrm{cm}^{2} 10^{3} ; \mathrm{p} 75: 5.38 \mathrm{ppm} / \mathrm{cm}^{2} 10^{3}$ ).

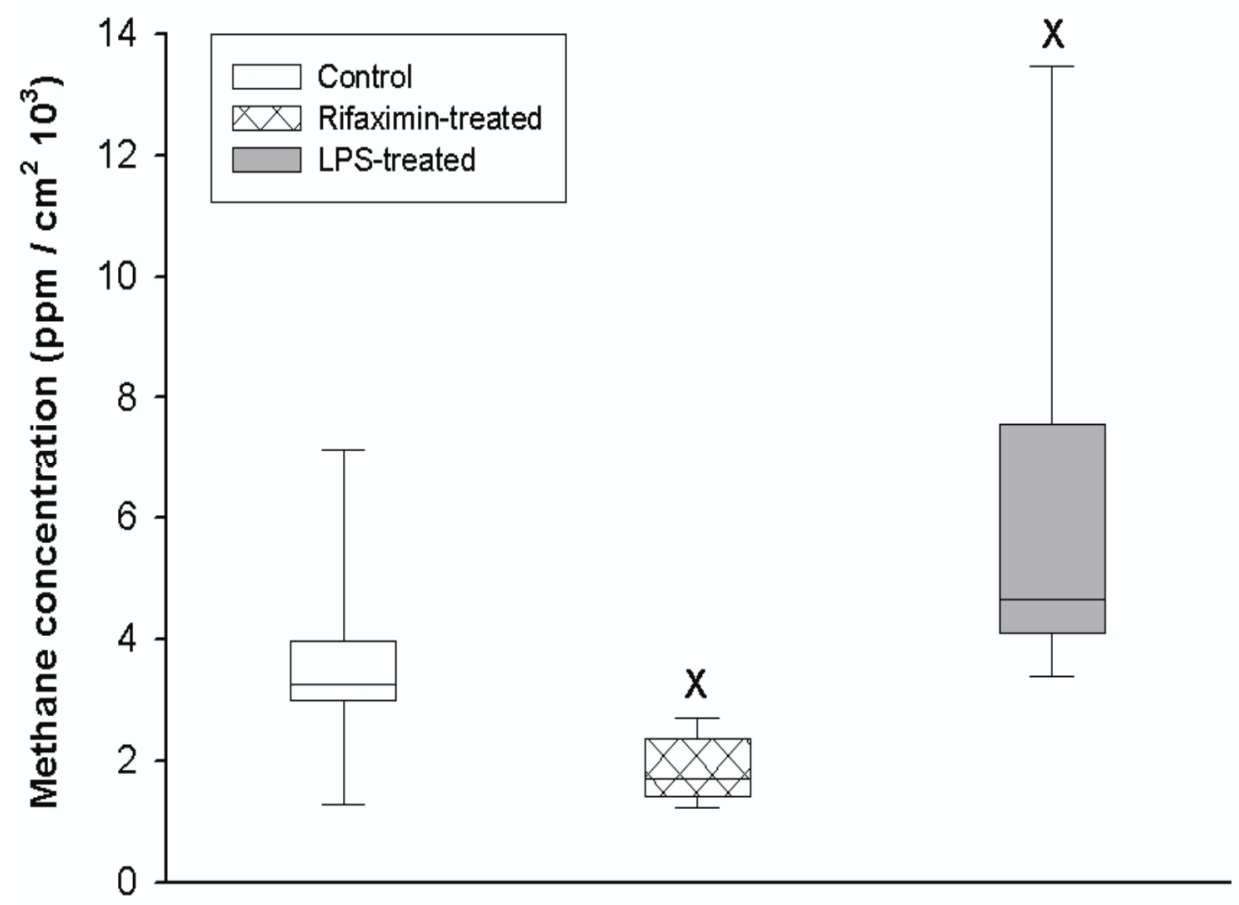

Figure 6. Whole-body $\mathrm{CH}_{4}$ production in mice. White box: untreated control group, hatched box: rifaximin-treated group, gray box: LPS-treated group. Median values and $75^{\text {th }}$ and $25^{\text {th }}$ percentiles are given. $\mathrm{p}<0.05$ was considered statistically significant. ${ }^{\mathrm{x}} \mathrm{p}<0.05$ vs. control. 


\section{3. $\mathrm{CH}_{4}$ concentration of the exhaled breath of humans}

The determined range was found to be between 0 and $36.9 \mathrm{ppm} .21 \%$ of the population proved to be $\mathrm{CH}_{4}$ producers. There was no difference between the males and females in cumulative $\mathrm{CH}_{4}$ production (figure 7) $(\mathrm{p}=0.831)$. The amount of the produced $\mathrm{CH}_{4}$ was higher among the adults than among children (figure 8) $(\mathrm{p}=0.079)$.

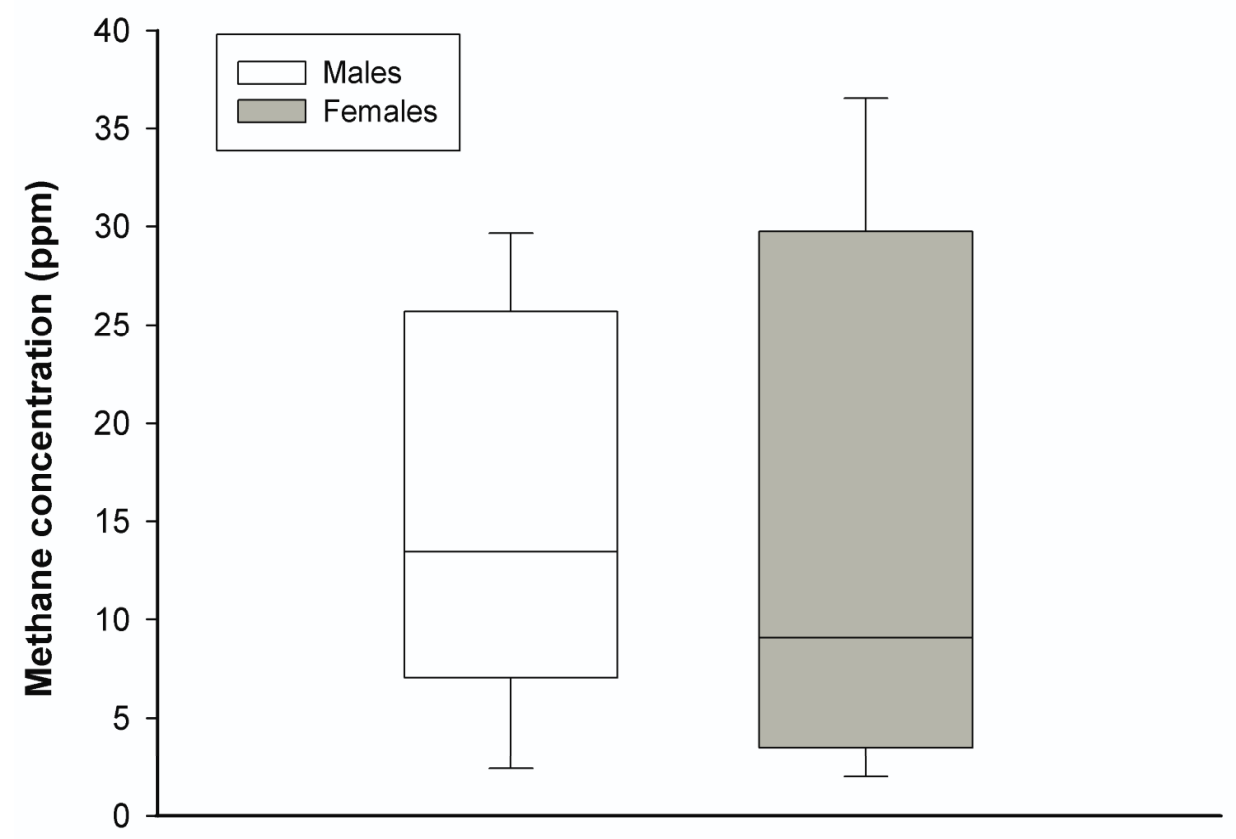

Figure 7. Exhaled $\mathrm{CH}_{4}$ concentrations in humans. The white boxes show data for adult males, while the gray boxes show data for adult females. Median values and $75^{\text {th }}$ and $25^{\text {th }}$ percentiles are given. 


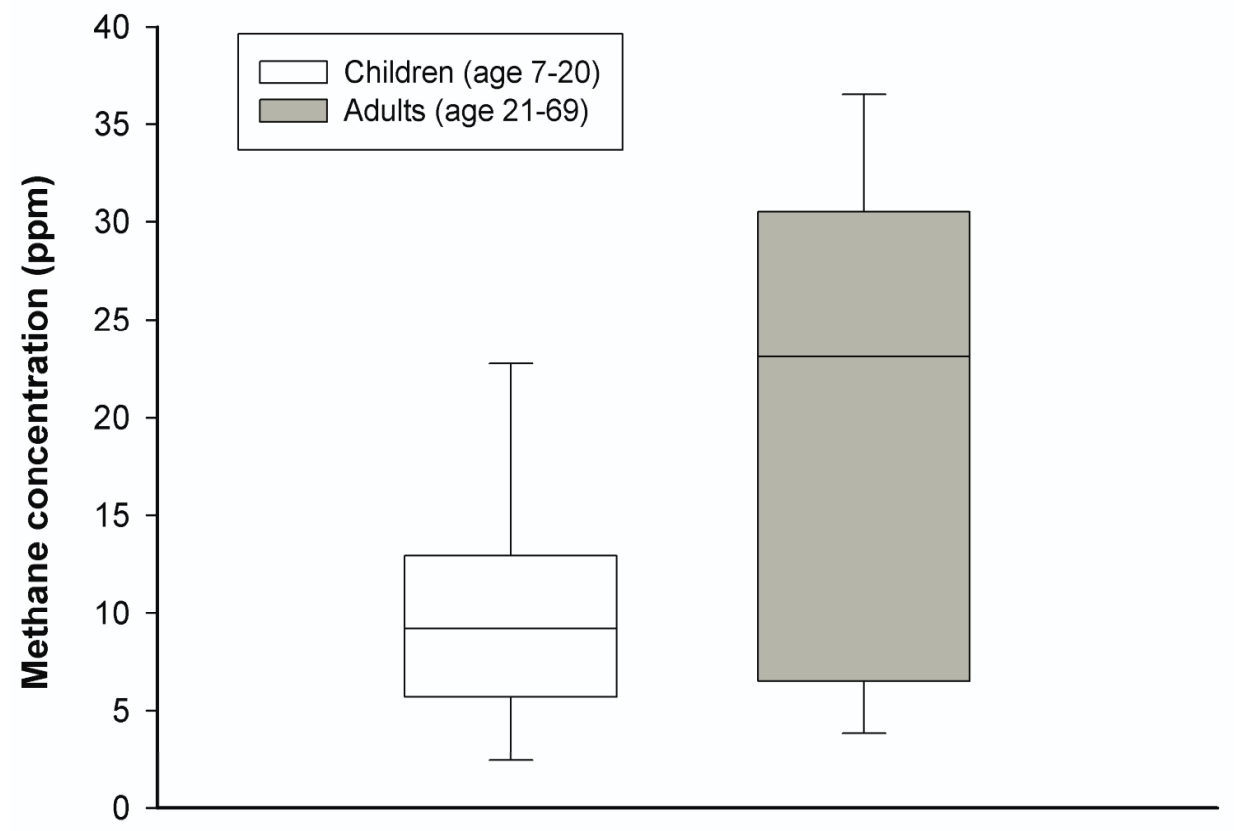

Figure 8. Exhaled $\mathrm{CH}_{4}$ concentrations in humans. The white boxes show data for children, while the gray boxes show data for adult overall. Median values and $75^{\text {th }}$ and $25^{\text {th }}$ percentiles are given.

\section{Discussion}

Biomarkers are useful tools through which to gain an understanding of human or animal pathophysiology and the biological response to therapy, and in this sense, the significance of biotic $\mathrm{CH}_{4}$ production is currently acquiring increased attention. It is clear that $\mathrm{CH}_{4}$ is released during stress conditions, and it has been suggested that the excretion of $\mathrm{CH}_{4}$ in the breath of mammals may reflect intestinal bacterial fermentation plus an unknown and variable degree of nonbacterial generation induced from target cells $[10,12]$. Nevertheless, whereas microbial methanogenesis has been reasonably well described, the details of the mechanism of the aerobic $\mathrm{CH}_{4}$ generation are basically undefined, and cellular sources are at present a subject of investigation.

GC is one of the most important and widely-used analytical methods for the determination of small amounts of organic substances such as $\mathrm{CH}_{4}$ in gas samples. In our study the $\mathrm{CH}_{4}$ measurements with the newly-developed PAS system correlated closely with the GC measurements. The detected 
$\mathrm{CH}_{4}$ changes were reproducible; the instrument is highly specific for $\mathrm{CH}_{4}$ and has a wide dynamic range, from levels of a few ppm to several thousands of ppm.

The $\mathrm{CH}_{4}$ detection by PAS was previously studied with different light sources and pressure detectors. For instance, Besson et al. were able to reach a $0.5 \mathrm{ppm}$ detection limit for $\mathrm{CH}_{4}(1 \mathrm{~s}$ integration time) with a PAS based sensor using a $1651 \mathrm{~nm}$ laser diode (10 $\mathrm{mW}$ output power) [31]. The quality factor of the resonator used in that system was 28 , consequently for practical applications time consuming resonance frequency tracking should be implemented. Scotoni et al. developed a nearinfrared (tunable between 1621-1661 nm) photoacoustic system for simultaneous detection of multiple gases $\left(\mathrm{CH}_{4}\right.$, ethylene $\left(\mathrm{C}_{2} \mathrm{H}_{4}\right)$ and $\left.\mathrm{NH}_{3}\right)$ [32], which had a detection limit of $6 \mathrm{ppm}$ for $\mathrm{CH}_{4}$ with a 0.3 $\mathrm{mW}$ laser power. Nevertheless, in order to achieve proper spectral resolution reduced pressure was required. Fundamental rovibrational bands of $\mathrm{CH}_{4}$ are in the mid-infrared range that is achievable with nonlinear optical devices (optical parametric oscillators - OPO), difference frequency generation and quantum cascade lasers (QCL). Ngai et al. measured $\mathrm{CH}_{4}$, ethane $\left(\mathrm{C}_{2} \mathrm{H}_{6}\right)$ and water vapor concentrations in the breath samples of two volunteers with a broadly tunable $(2.75-3.83 \mu \mathrm{m})$ OPO [33]. PAS using optical cantilever detection (based on broadband mid-infrared sources) have been developed and proved to have high sensitivity; with this method for $\mathrm{CH}_{4}$ a detection limit of $0.5 \mathrm{ppm}$ with $5 \mathrm{~s}$ integration time was achieved [34]. With a similar technique multicomponent analysis for industrial applications was performed, the limit of detection were $0.5 \mathrm{ppm}$ for $\mathrm{CH}_{4}$ and $4 \mathrm{ppm}$ for $\mathrm{CO}_{2}$, with a measurement time of $100 \mathrm{~s}$ [35]. Grossel et al. compared the performance of PAS based $\mathrm{CH}_{4}$ measuring system with a near-infrared diode laser $(1.65 \mu \mathrm{m})$ and with a mid-infrared QCL $(7.9 \mu \mathrm{m})$ [36]. The detection limit of their photoacoustic sensor was $0.15 \mathrm{ppm}$ for near-infrared and $3 \mathrm{ppb}$ for mid-infrared light (integration time was $1 \mathrm{~s}$ ). Despite this significant difference in the sensitivity the use of mid-infrared light sources for practical applications is not frequent currently due to their high cost (at least one order of magnitude more expensive than near-infrared diode lasers). From another point of view the utilization of mid-infrared sources in breath research is more reasonable for the measurement of breath constituents at ppb range (including NO) [37].

Near-infrared diode lasers still represent effective solution due to their excellent stability, robust and compact design, long-lifetime and low cost. These requirements must be fulfilled also by 
gas sensors for medical applications. Despite the fact that numerous high sensitivity PAS based $\mathrm{CH}_{4}$ sensor have been reported in the literature, their use for breath analysis is uncommon [33]. The presented instrument proved its applicability in three medical studies in which it could successfully substitute a gas chromatograph. It allows in-situ measurements in consequence of its robust and compact construction.

The presented instrument has low maintenance costs and operates without chemicals, and the gas-sampling procedure does not demand the use of disposable bags or syringes. The possible inaccuracies associated with adsorption-desorption processes were minimized by using inert materials for the setup. The use of the instrument does not require technical skill, and the utilization of commercially available, near-infrared diode lasers keeps the costs relatively low. In view of the longterm stability, control calibration is recommended only once a year. The range of application can easily be expanded by the addition of another light source to the system. PAS-based sensors have proved to be appropriate for multi-component analyses of widely varying gas compositions [31, 32, $35,38,39]$, indicating the potential for more complex gas analysis. The sampling chamber and the flow rate of the gas samples can be optimized for different experiments. Furthermore, the instrumentation can be used in acute or chronic experiments without exposing the animals to surgery, anesthesia or other trauma during the measurements.

In this study, the amounts of $\mathrm{CH}_{4}$ exhaled from the airways, together with those discharged through the skin and body orifices, were quantified by means of a whole-body $\mathrm{CH}_{4}$ detection setup, and acute endotoxemia was accompanied by an increasing emanation of endogenous $\mathrm{CH}_{4}$ throughout the experiments. The use of rifaximin, an antibiotic targeting the methanogenic bacterial flora, caused a decrease in $\mathrm{CH}_{4}$ release, but the production still significantly exceeded the control and background values. These findings led us to assume that nonbacterial $\mathrm{CH}_{4}$ production occurred besides the bacterial production, and at such a rate that it was impossible to detect it with the conventional techniques utilized to date.

Although the details of the reaction pathway for nonmicrobial $\mathrm{CH}_{4}$ formation are still unknown, anoxia-induced $\mathrm{CH}_{4}$ formation has previously been demonstrated in isolated mitochondria [9]. Nonbacterial $\mathrm{CH}_{4}$ release occurs in plant and animal cells in response to the specific blockade of 
mitochondrial complex IV $[8,9]$ and in rats during $\mathrm{NaN}_{3}$-induced chronic chemical hypoxia [10]. LPS activates cellular toll-like receptors and induces a generalized inflammatory reaction, with the production of reactive oxygen species production from multiple sources [40]. The $\mathrm{CH}_{4}$-generating capacity of $\mathrm{NaN}_{3}$ administration may also be associated with the generation of reactive oxygen species $[10,41,42]$, and it has been hypothesized that the electrophilic methyl groups of biomolecules such as choline or methionine might be carbon precursors $[2,7,10,11]$ and a potential source of $\mathrm{CH}_{4}$ generation in this scenario.

Even though the determination of the whole-body $\mathrm{CH}_{4}$ release of anesthetized or unrestrained smaller animals provides more comprehensive data in a living system, the breath test is the method of choice with which to monitor human $\mathrm{CH}_{4}$ production [15]. In clinical practice, breath gas analysis has been widely used for the screening of patients with irritable bowel disease, where the observation of $\mathrm{CH}_{4}$ concentration changes in relationship with other gaseous compounds can promote the diagnosis [43-45]. Given this background, the PAS system was tested for single-breath analysis as well, in order to collect representative data for a comparative human survey. The $\mathrm{CH}_{4}$ concentration in the breath is usually greater than $1 \mathrm{ppm}$ in only $30-60 \%$ of humans [15]. Regardless of sex and age, we found $21 \%$ producers, with a mean $\mathrm{CH}_{4}$ concentration of $15.4 \mathrm{ppm}$. This proportion is broadly in line with recent findings based on GC measurements, where the average breath $\mathrm{CH}_{4}$ concentration in adult $\mathrm{CH}_{4}$ producers was $16.6 \mathrm{ppm}$ [16]. Large differences in breath gas analysis data are presumably due to the variations in the personal background, but possibly also to inaccuracies of sampling and analysis techniques. Indeed, in another, comprehensive GC study, the prevalence of $\mathrm{CH}_{4}$ producers in different ethnic groups was scattered from $24 \%$ to $58 \%$ [45].

In summary, we have constructed a real-time, in-situ gas detection system for the in vivo measurement of $\mathrm{CH}_{4}$ levels. The method is reliable and suitable for the analysis of single-breath samples in humans, or of the whole-body $\mathrm{CH}_{4}$ release in smaller animals in different pathological states or after various treatments. Our present and previous findings lead us to conclude that the determination of endogenous $\mathrm{CH}_{4}$ may be a possible indicator of a sustained oxido-reductive imbalance, and the technique described here may be useful tool for the diagnostics of such events. 


\section{Acknowledgments}

The authors are grateful to Nikolett Beretka, Ágnes Lilla Kovács, Csilla Mester, Edina Markó, Károly Tóth and Kálmán Vas for their skilful assistance.

\section{Grant supports}

The study was supported by Hungarian Science Research Fund (OTKA) grants K104656, Social Renewal Operational Programme (TÁMOP)-4.2.2/A-11/1/KONV-2012-0035 and TÁMOP 4.2.2.A-11/1/KONV-2012-0060. This research was realized in the frames of TÁMOP 4.2.4. A/2-11-12012-0001 „National Excellence Program - Elaborating and operating an inland student and researcher personal support system convergence program". The project was subsidized by the European Union and co-financed by the European Social Fund.

\section{Disclosure}

The authors report no conflicts of interests. 


\section{References}

[1] Hartmann H and Ahring B K 2005 A novel process configuration for anaerobic digestion of source-sorted household waste using hyper-thermophilic post-treatment Biotechnol Bioeng. 90 830-7 [2] Shah E D, Basseri R J, Chong K and Pimentel M 2010 Abnormal breath testing in IBS: a metaanalysis Dig. Dis. Sci. 55 2441-9

[3] Keppler F, Hamilton J T, Brass M and Röckmann T 2006 Methane emissions from terrestrial plants under aerobic conditions Nature 439 187-91

[4] Vigano I, Van Weelden H, Holzinger R, Keppler F and Röckmann T 2008 Effect of UV radiation and temperature on the emission of methane from plant biomass and structural components Biogeosciences 5 243-70

[5] McLeod A R, Fry S C, Loake G J, Messenger D J, Reay D S, Smith K A and Yun B W 2008 Ultraviolet radiation drives methane emissions from terrestrial plant pectins New Phytol. 180 124-32

[6] Messenger D J, McLeod A R and Fry S C 2009 The role of ultraviolet radiation, photosensitizers, reactive oxygen species and ester groups in mechanisms of methane formation from pectin Plant Cell Environ. 32 1-9

[7] Brüggemann N, Meier R, Steigner D, Zimmer I, Louis S and Schnitzler J P 2009 Nonmicrobial aerobic methane emission from poplar shoot cultures under low-light conditions New Phytol. 182 91218

[8] Wishkerman A, Greiner S, Ghyczy M, Boros M, Rausch T, Lenhart K and Keppler F 2011 Enhanced formation of methane in plant cell cultures by inhibition of cytochrome $c$ oxidase Plant Cell Environ. 34 457-64

[9] Ghyczy M, Torday C, Kaszaki J, Szabó A, Czóbel M, Boros M 2008 Hypoxia-induced generation of methane in mitochondria and eukaryotic cells - an alternative approach to methanogenesis Cell Physiol. Biochem. 21 251-58

[10] Tuboly E, Szabó A, Garab D, Bartha G, Janovszky Á, Erős G, Szabó A, Mohácsi Á, Szabó G, Kaszaki J, Ghyczy M and Boros M 2013 Methane biogenesis during sodium azide-induced chemical hypoxia in rats Am. J. Physiol. Cell Physiol. 2 C207-C14 
[11] Ghyczy M, Torday C and Boros M 2003 Simultaneous generation of methane, carbon dioxide, and carbon monoxide from choline and ascorbic acid - a defensive mechanism against reductive stress? FASEB J. 9 1124-6

[12] Ghyczy M, Torday C, Kaszaki J, Szabó A, Czóbel M and Boros M 2008 Oral phosphatidylcholine pretreatment decreases ischemia-reperfusion-induced methane generation and the inflammatory response in the small intestine Shock 30 596-602

[13] Boros M, Ghyczy M, Érces D, Varga G, Tökés T, Kupai K, Torday C and Kaszaki J 2012 The anti-inflammatory effects of methane Crit. Care Med. 4 1269-78

[14] Le Marchand L, Wilkens L R, Harwood P and Cooney R V 1992 Use of breath hydrogen and methane as markers of colonic fermentation in epidemiologic studies: circadian patterns of excretion Environ. Health Perspect. 98 199-202

[15] Lacy Costello B P J, Ledochowski M and Ratcliffe N M 2013 The importance of methane breath testing: a review J. Breath Res. 7024001

[16] Levitt M D, Furne J K and Kuskowski M J 2006 Stability of human methanogenic flora over 35 years and a review of insights obtained from breath methane measurements Clin. Gastroenterol. Hepatol. 4 123-9

[17] Ligor T, Ligor M, Amann A, Ager C, Bachler M, Dzien A and Buszewski B 2008 The analysis of healthy volunteers' exhaled breath by the use of solid-phase microextraction and GC-MS J. Breath Res. 2046006

[18] Yu Y and Pawliszyn J 2004 On-line monitoring of breath by membrane extraction with sorbent interface coupled with $\mathrm{CO}_{2}$ sensor J. Chromatogr. A 1056 35-41

[19] Nose K, Nunome Y, Kondo T, Araki S and Tsuda T 2005 Identification of gas emanated from human skin: methane, ethylene, and ethane Anal. Sci. 21 625-8

[20] Cristescu S M, Persijn S T, Lintel Hekkert S T and Harren F J M 2008 Laser-based systems for trace gas detection in life sciences Appl. Phys. B 92 343-9

[21] Navas M J, Jiménez A M and Asuero A G 2012 Human biomarkers in breath by photoacoustic spectroscopy Clin. Chim. Acta 413 1171-8 
[22] Wang C and Sahay P 2009 Breath analysis using laser spectroscopic techniques: breath biomarkers, spectral fingerprints, and detection limits Sensors 9 8230-62

[23] Finegold S M, Molitoris D and Väisänen M L 2009 Study of the in vitro activities of rifaximin and comparator agents against 536 anaerobic intestinal bacteria from the perspective of potential utility in pathology involving bowel flora Antimicrob. Agents Chemother. 53 281-6

[24] Sigrist M W 1994 Air Monitoring by Spectroscopic Techniques vol 127, ed M W Sigrist (New York: Wiley)

[25] Michaelian K H 2010 Photoacoustic IR Spectroscopy 2nd ed (Weinheim: Wiley-VCH)

[26] Liang G C, Liu H H, Kung A H, Mohácsi Á, Miklós A and Hess P 2000 Photoacoustic trace detection of methane using compact solid-state lasers J. Phys. Chem. A 104 10179-83

[27] Bozóki Z, Pogány A and Szabó G 2011 Photoacoustic instruments for practical applications: present, potentials, and future challenges Appl. Spectrosc. Rev. 46 1-37

[28] Schilt S, Besson J P and Thévenaz L 2006 Near-infrared laser photoacoustic detection of methane: the impact of molecular relaxation Appl. Phys. B 82 319-29

[29] Eugster W and Kling G W 2012 Performance of a low-cost methane sensor for ambient concentration measurements in preliminary studies Atmos. Meas. Tech. 5 1925-34

[30] Rothman L S, Jacquemart D, Barbe A, Benner D C, Birk M, Brown L R, Carleer M R, Chackerian C, Chance K, Dana V, Devi V M, Flaud J M, Gamache R R, Goldman A, Hartmann J M, Jucks K W, Maki A G, Mandin J Y, Massie S T, Orphal J, Perrin A, Rinsland C P, Smith M A H, Tennyson J, Tolchenov R N, Toth R A, Vander A J, Varanasi P and Wagner G 2005 The HITRAN 2004 molecular spectroscopic database J. Quantum Spectrosc. Radiat. Transf. 96 139-204

[31] Besson J P, Schilt S and Thevenaz L 2004 Multi-gas sensing based on photoacoustic spectroscopy using tunable laser diodes Spectrochim. Acta A $603449-56$

[32] Scotoni M, Rossi, A, Bassi D, Buffa R, Iannotta S and Boschetti A 2006 Simultaneous detection of ammonia, methane and ethylene at $1.63 \mu \mathrm{m}$ with diode laser photoacoustic spectroscopy Appl. Phys. B 82 495-500 
[33] Ngai A K Y, Persijn S T, von Basum G and Harren F J M 2006 Automatically tunable continuous-wave optical parametric oscillator for high-resolution spectroscopy and sensitive trace-gas detection Appl. Phys. B 85 173-80

[34] Fonsen J, Koskinen V, Roth K and Kauppinen J 2009 Dual cantilever enhanced photoacoustic detector with pulsed broadband IR-source J. Vib. Spectrosc. 50 214-7

[35] Hirschmann C B, Uotila J, Ojala S, Tenhunen J and Keiski R L 2010 Fourier transform infrared photoacoustic multicomponent gas spectroscopy with optical cantilever detection Appl. Spectrosc. 64 $293-7$

[36] Grossel A, Zeninari V, Joly L, Parvitte B, Courtois D and Durry G 2006 New improvements in methane detection using a Helmholtz resonant photoacoustic laser sensor: A comparison between near-IR diode lasers and mid-IR quantum cascade lasers Spectrochim. Acta A 63 1021-8

[37] Spagnolo V, Kosterev A A, Dong L, Lewicki R and Tittel F K 2010 NO trace gas sensor based on quartz-enhanced photoacoustic spectroscopy and external cavity quantum cascade laser Appl. Phys. B

$100125-30$

[38] Hanyecz V, Mohácsi Á, Pogány A, Varga A, Bozóki Z, Kovács I and Szabó G 2010 Multicomponent photoacoustic gas analyzer for industrial applications Vib. Spectrosc. 52 63-8

[39] Kosterev A A, Dong L, Thomazy D, Tittel F K and Overby S 2010 QEPAS for chemical analysis of multi-component gas mixtures Appl. Phys. B 101 649-59

[40] Park H S, Jung H Y, Park E Y, Kim J, Lee W J and Bae Y S 2004 Cutting edge: direct interaction of TLR4 with $\mathrm{NAD}(\mathrm{P}) \mathrm{H}$ oxidase 4 isozyme is essential for lipopolysaccharide-induced production of reactive oxygen species and activation of NF-אB J. Immunol. 173 3589-93

[41] Smith T S and Bennett J P 1997 Mitochondrial toxins in models of neurodegenerative diseases. I: in vivo brain hydroxyl radical production during sytemic MPTP treatment or following microdialysis infusion of methylpyridinium or azide ions Brain Res. 765 183-8

[42] Duranteau J, Chandel N S, Kulisz A, Shao Z and Schumacker P T 1998 Intracellular signaling by reactive oxygen species during hypoxia in cardiomyocytes J. Biol. Chem. 273 11619-24

[43] Peled Y, Weinberg D, Hallak A and Gilat T 1987 Factors affecting methane production in humans Dig. Dis. Sci. 3 267-71 
[44] Bratten J R and Jones M P 2007 Small intestinal motility Curr. Opin. Gastroenterol. 23 127-33

[45] Pitt P, De Bruijn K M, Beeching M F, Goldberg E and Blendis L M 1980 Studies on breath methane: the effect of ethnic origins and lactulose Gut $21951-4$ 